\title{
Uma experiência turística no trem de passageiros da Estrada de Ferro Vitória a Minas
}

Willi Jardim Costa Klink ${ }^{\mathrm{a}}$

\section{Resumo}

Em razão de consecutivas decisões políticas e ações governamentais em âmbito nacional, a oferta de transporte ferroviário de passageiros no Brasil se concentra, principalmente, no transporte férreo urbano presente em algumas áreas metropolitanas populosas. Há raros exemplos de trens que transportam passageiros de longa distância e alguns poucos trens turísticos que operam trechos curtos e, nem sempre, tem frequência regular. Um dos trechos ferroviários que conta com trem de passageiros, diários e regulares é o da Estrada de Ferro Vitória a Minas, operado pela empresa Vale, que liga as capitais Vitória-ES e Belo Horizonte-MG. Este estudo constitui-se em uma pesquisa exploratóriadescritiva, que empregou a técnica de observação participante, para concretizar o objetivo de registrar as experiências de um passageiro-turista, vividas pelo pesquisador, ao realizar o referido percurso. Como resultado detectou-se que apesar do serviço de passageiros ser oferecido para atender moradores da região e constituir-se em um fator que promove o desenvolvimento regional, ele também apresenta características que podem ser aproveitadas por turistas e por operadoras turísticas.

Palavras-chave: Transporte ferroviário de passageiros; Turismo ferroviário; Serviços turísticos; Estrada de Ferro Vitória a Minas; Desenvolvimento regional.

\begin{abstract}
A tourist experience at the passenger train of the Vitória-Minas Railroad Due to consecutive political decisions and governmental actions nationwide, the supply of rail passenger transport in Brazil is mainly focused in the urban rail transport present in some populous metropolitan areas. There are rare examples of trains carrying long distance passengers and a few tourist trains that operate short stretches and, not always, have regular frequency. One of the railway sections that has passenger trains, daily and regularly is the Vitória-Minas Railroad, operated by the company Vale, which links the capitals Vitória-ES and Belo Horizonte-MG. This study is based on an exploratorydescriptive research, which used the participant's observation technique, in order to achieve the objective of registering the experiences of a passenger-tourist, lived by the researcher, when carrying out the aforementioned route. As a result, it was detected that although the passenger service was offered to serve the region's residents and constitute a factor that promotes regional development, it also presents characteristics that can be enjoyed by tourists and tour operators.

Keywords: Rail transport of passengers; Railway tourism; Tourist services; VitóriaMinas Railway; Regional development.
\end{abstract}

a. Graduando em Turismo e pesquisador de Iniciação Científica pela Escola de Comunicações e Artes da Universidade de São Paulo (ECA-USP), São Paulo, SP, Brasil.E-mail: willi.klink@usp.br 


\section{Resumen}

\section{Una experiencia turística en el tren de pasajeros de la Ferrocarril Vitória a Minas}

En consecuencia de consecutivas decisiones políticas y acciones gubernamentales a nivel nacional, la oferta de transporte ferroviario de pasajeros en Brasil se concentra, principalmente, en el transporte férreo urbano presente en algunas áreas metropolitanas populosas. Hay raros ejemplos de trenes que transportan pasajeros de larga distancia $\mathrm{y}$ algunos pocos de trenes turísticos que operan tramos cortos y, no siempre, tienen frecuencia regular. Uno de los tramos ferroviarios que cuenta con tren de pasajeros, diarios y regulares es el de la Ferrocarril Vitória a Minas, operado por la empresa Vale, que conecta las capitales Vitória-ES y Belo Horizonte-MG. Este estudio se constituye en una investigación exploratoria-descriptiva, que empleó la técnica de observación participante, para concretar el objetivo de registrar las experiencias de un pasajeroturista, vividas por el investigador, al realizar dicho recorrido. Como resultado se ha detectado que a pesar de que el servicio de pasajeros es oferecido para atender a los residentes de la región y constituirse en un factor que promueve el desarrollo regional, también presenta características que pueden ser aprovechadas por turistas y por operadores turísticos.

Palabras clave: Transporte ferroviario de pasajeros; Turismo ferroviario; Servicios turísticos; Ferrocarril Vitória a Minas; Desarrollo regional.

\section{INTRODUÇÃo}

O transporte ferroviário do Brasil teve o seu início na década de 1850 com a criação de ferrovias pelo país, devido a idealização do empreendedor Irineu Evangelista de Souza, conhecido como o Barão de Mauá. Essas ferrovias se expandiram acompanhando o crescimento da atividade cafeeira e tinham como principal objetivo escoar a produção agrícola do interior do país para os portos, visando a exportação (Palhares, 2002).

Neste período, a criação de linhas férreas para o escoamento de produção agrícola e extração mineral foi comum em países como a Argentina, África do Sul e o Brasil, conhecidos por suas economias exportadoras, e que fizeram uso de corredores férreos para promover uma alavancagem econômica. Porém, esse crescimento das linhas férreas brasileiras foi pautado por uma desordem institucional regulatória e uma falta de planejamento na malha, o que ocasionou a criação de ferrovias com diferentes tipos de bitolas, e que, hoje inviabiliza uma integração nacional plena do modal (Fraga \& Castro, 2012; CNT, 2013).

O sistema ferroviário brasileiro começou a entrar em decadência a partir da década de 1920 com a crise mundial que afetou a exportação do café e com os novos direcionamentos que a industrialização do país impunha às instâncias políticas. Na década de 1950 a decadência das ferrovias se intensificou com a criação de políticas públicas rodoviaristas, que acirraram a concorrência entre estes dois setores de transporte, considerando tanto cargas quanto passageiros. assim o modal ferroviário perdeu receitas e amargou uma redução de investimentos em infraestrutura (estradas e estações) e modernização de equipamentos. (Palhares, 2002; CNT, 2013).

Quarenta anos depois o modal ferroviário retoma a sua operação no Brasil após a implantação de políticas de incentivo e de desestatização da década de 
1990 e tem como principal objetivo a exportação de minérios e de granéis (Palhares, 2002; Fraga \& Castro, 2012).

0 transporte de passageiros através do modal férreo é representado, em sua maior parte, pelos transportes urbanos sobre trilhos, de curto percurso (Lohmann, Fraga \& Castro, 2013). Constituem-se como transportes férreos urbanos, os trens metropolitanos, os metrôs, os monotrilhos, os veículos leves sobre trilhos (VLT), os bondes e os funiculares (Fraga \& Castro, 2012; CNT, 2016). Além dos bondes e dos funiculares, o transporte ferroviário urbano:

[...] apresenta, em geral, pequena importância do ponto de vista do turista quando comparado com o transporte ferroviário de passageiros de médio e longo percurso. Isso ocorre principalmente porque sua operação se restringe aos grandes centros metropolitanos, nos quais os passageiros geralmente movimentam-se dentro de seus ambientes usuais de convivência (Palhares, 2002, p. 284-285).

A outra parcela que representa os transportes ferroviários de passageiros é, em sua maioria, destinado ao segmento turístico. São linhas férreas de pequeno e médio percurso voltadas a viagens cênicas e históricas, que geram sentimentos nostálgicos aos turistas e, normalmente, são realizadas em carros panorâmicos. São também transportes vistos como próprio atrativo turístico (Palhares, 2002; Allis, 2006; Fraga, 2011). Estas linhas estão, predominantemente, localizadas nas regiões Sudeste e Sul do país (Brasil, MT, 2015).

Somente duas linhas férreas regulares de longa distância operam no Brasil para transportes de passageiros, a Estrada de Ferro Carajás (EFC) e a Estrada de Ferro Vitória a Minas (EFVM), ambas operadas pela empresa Vale, voltadas para o transporte de minérios, mas também valorizam o transporte de passageiros como elemento promotor do desenvolvimento regional, não considerando, necessariamente, o cunho turístico do trem ou do percurso. (Fraga, 2011; Vale, 2017a; Vale, 2017b). Em concordância, Fraga e Castro (2012) apontam que, a escassez de trens de longa distância voltados para passageiros no Brasil, pode induzir o componente acionador da experiência turística voltado a "raridade" do serviço.

A EFVM é uma linha férrea que interliga as minas de minério de ferro de Minas Gerais com o Complexo Portuário de Tubarão, na Zona Metropolitana de Vitória, Espírito Santo. A ferrovia teve o seu primeiro trecho inaugurado no ano de 1904 e a sua conclusão se deu por volta da década de 1940. Foi estatizada em 1942 e passou a ser controlada pela Companhia Vale do Rio Doce. Em 1997 a estatal foi privatizada e, em 2007, alterou o seu nome para Vale. Atualmente a ferrovia possui cerca de $900 \mathrm{~km}$ de extensão e transporta cerca de 115 milhões de toneladas de minério de ferro e 27 milhões de toneladas de outras cargas por ano. (Vale, 2017b).

A EFVM também possui transporte de passageiros, que iniciou suas atividades quando da inauguração da ferrovia em 1904. Os passageiros eram transportados em carros de madeira acoplados a uma composição de carga. Isso foi modificado com a estatização da linha férrea, onde os passageiros passaram a ser transportados em composições únicas. Por volta da década de 1950 os carros de madeira foram substituídos por carros de aço e em 2014 a Vale adquiriu dois novos trens de passageiros modernizados. (Vale, 2017b). 
Ao analisar a oferta do trem de passageiros da EFVM como um dos únicos trens de passageiros de longa distância do país, estabelece-se como problema de pesquisa: 0 percurso do trem de passageiros da EFVM é uma experiência turística? Visto que Fraga (2011) destaca que o aproveitamento de trens de passageiros, não exclusivos do uso turístico, podem proporcionar um valor de experiência turística aos passageiros. Portanto o objetivo geral deste trabalho foi fixado em:

Fornecer um relato das experiências vividas pelo pesquisador ao realizar o percurso do trem de passageiros da EFVM, como turista.

Para atender ao objetivo geral, os seguintes objetivos específicos foram estabelecidos:

Fazer registros fotográficos;

Descrever a infraestrutura do trem, da via e das estações;

Descrever os serviços oferecidos aos passageiros, e;

Indicar os elementos que favorecem a experiência turística e os que a prejudicam.

\section{PROCEDIMENTOS METODOLÓGICOS}

O presente trabalho é o resultado de uma pesquisa exploratória-descritiva, uma vez que, segundo Vael (2011) pesquisas nestas categorias visam uma sondagem sobre o estado do objeto e uma descrição de suas características mais relevantes visando o objetivo proposto. Ela possui caráter exclusivamente qualitativo porque não emprega qualquer método de quantificação ou amostragem, e foi viabilizada pela técnica de observação participante, cujos preceitos visam a observação científica do pesquisador no momento em que participa dos acontecimentos visto como objeto de estudo (Veal, 2011).

A observação participante foi realizada entre os dias 13 e 14 de outubro de 2017, durante o feriado nacional, prolongado, de Nossa Senhora Aparecida iniciado na quinta-feira, dia 12 de outubro. Para tanto, o pesquisador realizou a compra das passagens do trem via internet, na classe econômica, a um valor de $\mathrm{R} \$ 42,00$ pelo trecho entre Estação Pedro Nolasco e Estação Governador Valadares e $\mathrm{R} \$ 42,00$ para o trecho entre Estação Governador Valadares e Estação Belo Horizonte. Embarcou em um avião na quinta-feira (12) partindo de São Paulo-SP com destino à Vitória-ES, e neste dia conheceu a capital Capixaba, bem como o Museu Ferroviário da Vale, que fica próximo ao local de embarque para o trecho ferroviário, objeto deste relato.

No dia seguinte (13), o pesquisador iniciou a observação participante ao se dirigir para a Estação Pedro Nolasco em Cariacica-ES, na Região Metropolitana de Vitória, para embarcar, às 07:00 horas, no trem de passageiros da EFVM, único horário diário de partida do trem de passageiros nas proximidades de Vitória-ES. Realizou-se o primeiro percurso, que durou 06:06 horas, até a cidade de Governador Valadares-MG, onde aconteceu o desembarque planejado pelo pesquisador. Optou-se pelo pernoite em Governador Valadares, visto a longa duração do percurso completo que é estimado em 13:30 horas, que poderia acarretar em cansaço excessivo, porque o trem não oferece carros com leito, e gerar eventuais interferências na imparcialidade da pesquisa. 
No Sábado (14), às 13:14 horas, o pesquisador continuou a viagem no trem, embarcando em Governador Valadares, em uma outra composição proveniente de Vitória com destino a Belo Horizonte-MG, tendo este trecho a duração total de 07:16 horas. 0 pesquisador permaneceu então na capital mineira no Domingo (15) para avaliar a Estação Ferroviária de Belo Horizonte, e, à noite, embarcou em um avião para retornar a São Paulo.

É importante ressaltar que mesmo a classe tarifária comprada pelo pesquisador fosse a econômica, foi possível andar e avaliar todos os carros das composições, uma vez que o trânsito de pessoas entre os carros é autorizado e incentivado através dos anúncios sonoros realizados durante o percurso.

Na sequência são apresentadas as características da EFVM, do percurso e da estrada de ferro, das estações ferroviárias visitadas; depois são analisados os equipamentos e serviços das composições de passageiros utilizadas (trens). Por fim, é feita a análise sobre a potencialidade turística da viagem de trem sob as teorias de Palhares (2002), Cooper et al. (2007) e Fraga (2011), que defende o transporte como atração turística a partir do momento que se tornam presentes uma oferta cênica e/ou uma oferta de sentimentos nostálgicos, através de resgates históricos. Destaca-se que são utilizados quadros e figuras, no decorrer do texto, para reunir e revelar dados e fotos, registradas em campo, ilustrando as informações relatadas.

\section{EXPERIÊNCIA COMO PASSAGEIRO-TURISTA NA EFVM}

Para maior compreensão este capítulo está dividido em site da EFVM, percurso, estações visitadas.

\section{Site da EFVM}

A Vale possui um portal online destinado as três linhas férreas de transporte de passageiros que ela opera, são elas: a Estrada de Ferro Vitória a Minas, a Estrada de Ferro Carajás e o Trem Turístico Ouro Preto-Mariana (Vale, 2017a). Ao selecionar a EFVM, ocorre o direcionamento para uma página a parte destinada exclusivamente a informações pertinentes a este trem.

0 site do trem de passageiros da EFVM é dividido em quatro páginas principais (Vale, 2017c). A primeira página fornece informações gerais sobre o trem, como a agenda cultural de atividades, dicas para o viajante, uma calculadora de preços e horários, jogos interativos online e uma área de download de imagens do trem para souvenirs.

Na página denominada rotas ocorre o discurso sobre o percurso do trem. Há um mapa interativo onde o visitante pode clicar sobre algumas estações do percurso para receber informações sobre a cidade, com textos e vídeos, além de links externos que direcionam as páginas das prefeituras dos municípios selecionados (Vale, 2017d). Ao fim da página, se localizam informações sobre pontos de venda físicos, direcionamento para compras online e dicas para a viagem.

Na página denominada informações sobre a viagem o site apresenta dicas sobre como realizar a viagem com conforto e segurança (Vale, 2017e). Apresenta 
também uma área de perguntas frequentes, com separações por temas, como compra de passagens, alterações nas passagens, embarque no trem e alimentação a bordo. Ao fim da página apresenta-se um informativo do Serviço de Atendimento ao Consumidor (SAC) denominado Alô Ferrovias!, um número de telefone gratuito com atendimento $24 \mathrm{~h}$ e acessível para deficientes auditivos.

Na página nomeada como conheça nossa frota é possível encontrar vídeos sobre a Vale e a EFVM, bem como, sobre o uso do entretenimento e da alimentação a bordo (Vale, 2017b). Ao fim da página são apresentadas informações sobre as particularidades dos carros econômicos, executivos, especial, lanchonete e restaurante, bem como o vagão cultural e o carro ambiental, que serão abordados mais adiante neste estudo.

Quase todas as páginas do site direcionam a página de reservas da Vale. Esta é uma página apontada como segura nos navegadores utilizados para a reserva. Nela é possível escolher dentre as três opções de trens que a Vale opera, indicar a origem e o destino, o percurso de ida e volta, ou somente ida, as datas da viagem, as classes (econômica, executiva ou cadeirante) e a quantidade de passagens desejada. Há também a possibilidade de compras de passagens com benefícios assegurados por Lei, como o Benefício idoso, o Passe para pessoas com deficiências, Bilhete de viagem do Jovem de Baixa Renda e Passe para crianças de colo. As especificidades de cada passagem com benefícios são descritas na Cartilha de Regras de Uso da Vale (2017f).

Após o cálculo da tarifa, apresenta-se um resumo da passagem e solicita-se a leitura e concordância virtual do Contrato de Transporte Ferroviário. Para continuar, o visitante necessita realizar um cadastro no sistema, com suas informações de contato. Ocorre a identificação do passageiro, e a escolha de um assento em um carro já pré-selecionado pela empresa. 0 pagamento da passagem é realizado no cartão de crédito, podendo ser parcelado em até 5 vezes, com parcelas mínimas no valor de $\mathrm{R} \$ 20,00$. Um voucher eletrônico é enviado para o endereço de e-mail informado e nele há a descrição de que é necessária a troca do voucher por um bilhete físico na estação e no dia de embarque, com no mínimo 30 minutos de antecedência a partida do trem.

\section{Percurso}

O trem de passageiros da EFVM percorre uma distância total de $664 \mathrm{~km}$, passando por cidades dos Estados de Espírito Santo e Minas Gerais. São dois trens que realizam o percurso diariamente. Às $7 \mathrm{~h}$ um trem parte da estação de Pedro Nolasco no município de Cariacica, na Região Metropolitana de Vitória, ES, enquanto as 7h30 um outro trem parte da Estação Ferroviária de Belo Horizonte, em Minas Gerais. Por volta das $13 \mathrm{~h} 40$ os trens se cruzam na região próxima a estação de Pedra Corrida, MG, momento este anunciado no sistema sonoro de informações do trem. Caso não ocorram atrasos, os trens chegam às estações finais a noite, $20 \mathrm{~h} 10$ em Belo Horizonte e $20 \mathrm{~h} 30$ em Cariacica, para então, no dia seguinte, realizar novamente o percurso no sentido inverso.

Os trens principais realizam embarques e desembarques em 17 estações e 12 paradas em cidades mineiras e capixabas pelo percurso, sendo as estações aquelas que possuem guichês para venda de passagens enquanto as paradas so- 
mente realizam o embarque e o desembarque. No total são 29 interrupções em 28 municípios, como ilustrado na Figura 1, elaborado pelo pesquisador com base em informações colhidas em campo e no site da Vale (2017c).

Figura 1- Mapa do percurso do Trem de Passageiros da EFVM

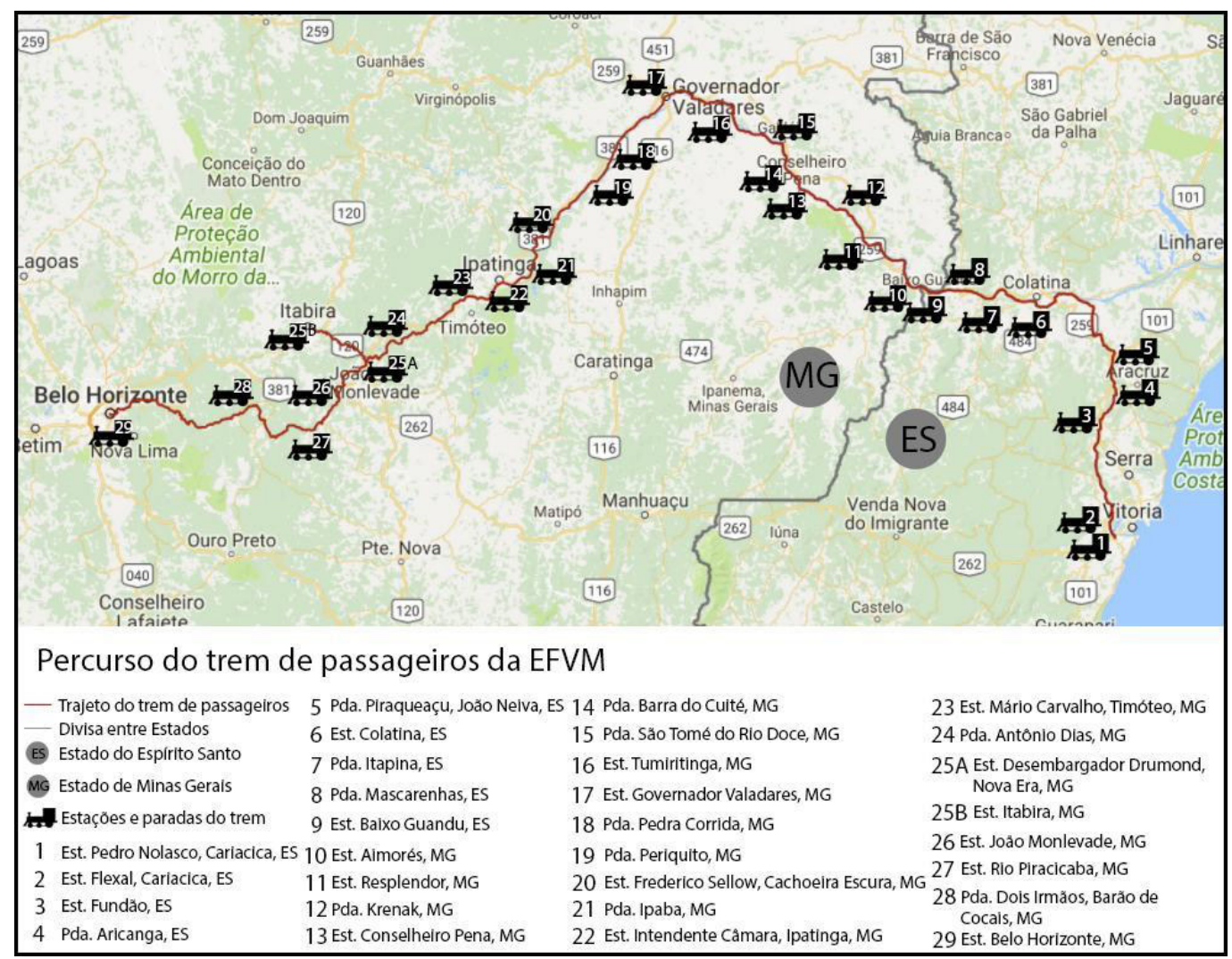

Fonte: Willi Jardim Costa Klink, 2017.

Além dos dois trens principais, a Vale conta com um trem auxiliar que realiza o percurso entre as estações de Desembargador Drumond-MG e Itabira-MG. Trata-se de um trem de poucos carros que perfaz quatro saídas diárias, com horários próximos aos dos trens principais, para atender o grande fluxo de viajante entre estas localidades. 0 pesquisador realizou somente a viagem nos dois trens principais, não avaliando o trem auxiliar.

A paisagem durante o percurso é diferenciada em função de seu caráter cênico, durante a maior parte do trajeto o trem margeia o Rio Doce, e após a estação de Intendente Câmara-MG o trem inicia um trajeto de curvas em aclive pelos mares de morros mineiros (Figura 2), com diversas encostas íngremes e túneis. 
Figura 2- Paisagem cênica que permeia a EFVM

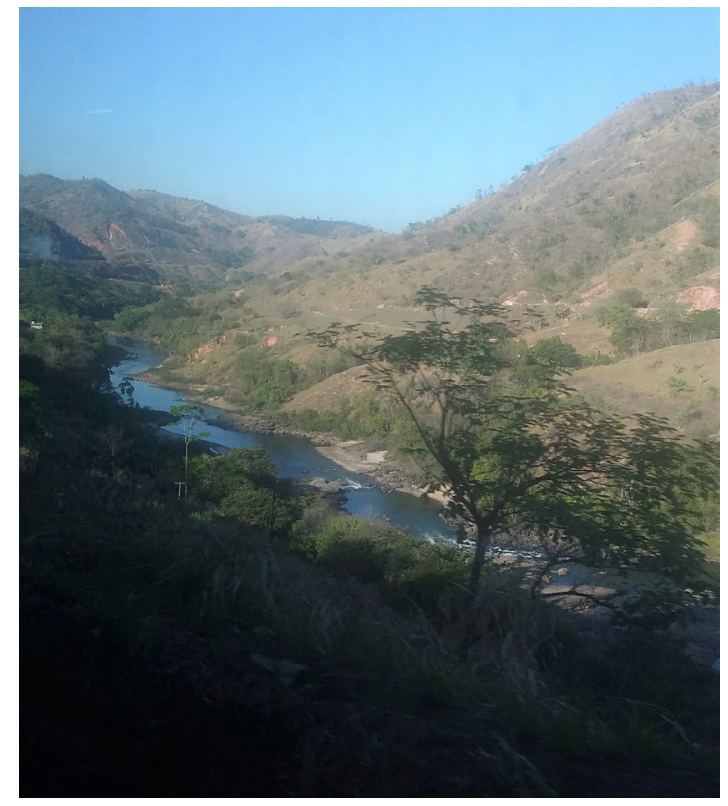

Fonte: Willi Jardim Costa Klink, 2017.

Próximo a cidade de Belo Horizonte, o trem realiza uma parada planejada de 15 minutos, foi anunciado que o trem estava deixando a área do centro de controle operacional da Vale em Vitória e entrando no centro de controle operacional de Belo Horizonte. Este centro de Belo Horizonte realiza o controle dos trens na Ferrovia Centro Atlântica, que possui bitola de tamanho 1,60m (Vale, 2017d), portanto, o trem de passageiros, em teoria, não seria compatível com o tamanho da bitola desta ferrovia, uma vez que a EFVM possui bitola métrica (Vale, 2017d), com distâncias entre trilhos de 1,00 metro, sendo os seus carros e vagões adaptados somente a esta bitola.

Este empecilho foi contornado com a implantação de uma bitola mista, são três trilhos paralelos que comportam trens das duas bitolas, comprovado pela Figura 3, quando o pesquisador presenciou as duas bitolas ao andar pela cidade de Belo Horizonte.

Figura 3 - Bitola mista em Belo Horizonte

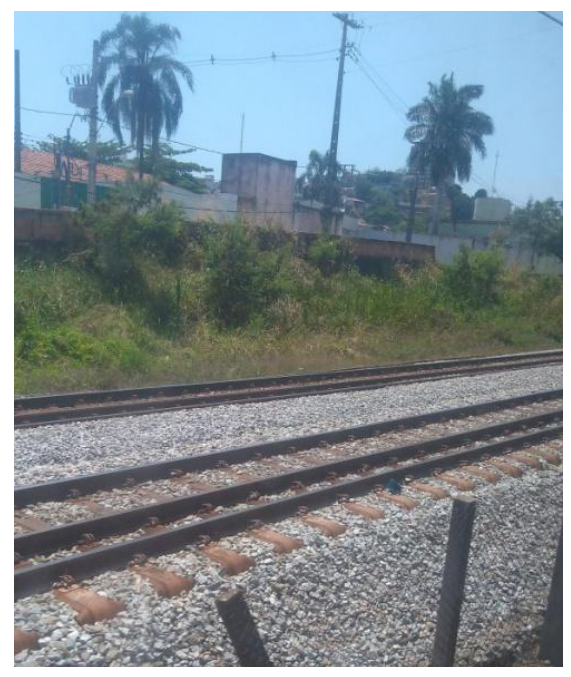

Fonte: Willi Jardim Costa Klink, 2017. 
Durante todo o percurso, percebeu-se em conversas entre os passageiros, e também conversas do pesquisador com passageiros, que eles consideram o trem de passageiros como um modal de transporte, sem agregar um valor turístico pela experiência da viagem. Muitos estavam realizando pequenos percursos entre cidades do trajeto do trem e não o seu percurso total. Tal constatação confirma que o trem serve para a locomoção de moradores da região e influencia a economia das localidades.

Para aqueles passageiros que realizavam o percurso total, entre as capitais dos dois estados, o trem é visto como um meio que compensa no valor da passagem, mesmo que o tempo do percurso seja maior do que outros meios de transportes, como descrito no Quadro 1, elaborado a partir de dados da Vale (2017c), dos sites de comparativos de passagens de ônibus ClickBus (2017) e de comparativos de passagens aéreas Decolar (2017).

Quadro 1 - Comparativos de preços e duração de viagens entre modais ferroviário, rodoviário e aéreo

\begin{tabular}{|l|l|l|}
\hline \multicolumn{2}{c}{ Percurso Vitória, ES - Belo Horizonte, MG } \\
\hline \multicolumn{1}{|c|}{ Modal } & \multicolumn{1}{c|}{ Preço } & \multicolumn{1}{c|}{ Duração da viagem } \\
\hline Trem da EFVM & $\mathrm{R} \$ 73,00$ & $13 \mathrm{~h} 30$ \\
\hline Ônibus & $\mathrm{R} \$ 100,00 \sim \mathrm{R} \$ 105,00$ & $9 \mathrm{~h} 30$ \\
\hline Avião & $\mathrm{R} \$ 180,00 \sim \mathrm{R} \$ 270,00$ & $1 \mathrm{~h} 15$ \\
\hline
\end{tabular}

Fonte: Adaptado de Vale (2017c), ClickBus (2017) e Decolar (2017)

Destaca-se que o pesquisador presenciou um atraso referente ao tempo de chegada a Belo Horizonte, o desembarque foi liberado na cidade por volta da 20h30, 20 minutos depois do tempo previsto para a chegada. Isso aconteceu devido a uma parada no meio do percurso, anunciada no sistema de informações como uma avaria no trem de carga localizado a frente ao dos passageiros. Foi informado que as providências estavam sendo tomadas para a liberação da via e a continuidade da viagem, ao todo foram 15 minutos parados. No primeiro trecho entre Cariacica e Governador Valadares não ocorram atrasos e o desembarque foi autorizado às $13 \mathrm{~h} 06$ na estação, como previsto.

Destaca-se que o pesquisador presenciou um atraso referente ao tempo de chegada a Belo Horizonte, o desembarque foi liberado na cidade por volta da 20h30, 20 minutos depois do tempo previsto para a chegada. Isso aconteceu devido a uma parada no meio do percurso, anunciada no sistema de informações como uma avaria no trem de carga localizado a frente ao dos passageiros. Foi informado que as providências estavam sendo tomadas para a liberação da via e a continuidade da viagem, ao todo foram 15 minutos parados. No primeiro trecho entre Cariacica e Governador Valadares não ocorram atrasos e o desembarque foi autorizado às $13 \mathrm{~h} 06$ na estação, como previsto. 


\section{Estações visitadas}

Devido ao pernoite planejado pelo pesquisador, foram visitadas e analisadas três estações no percurso, descritas a seguir.

\section{Estação Pedro Nolasco, Cariacica-ES}

Como dito anteriormente, a estação de Pedro Nolasco, está localizada no município de Cariacica, na Região Metropolitana de Vitória, ES. (Figura 4) A estação é acessível de transporte público somente por meio de ônibus intermunicipais. Foi presenciado que taxistas e motoristas da região, em sua maioria, sabem da existência da estação, porém desconhecem o destino do trem de passageiros que ali opera.

A estação é moderna, ampla e limpa, porém carece de uma informação visual eficiente. Diversas pessoas pareciam perdidas quanto às ações a serem realizadas. Para aqueles que compraram pela internet era necessário retirar o bilhete físico do trem, mediante a apresentação do voucher de compra e um documento de identificação oficial. Um profissional da estação estava postado no meio do saguão, para distribuir estas passagens já impressas, não havia nenhuma informação visual ou sonora sobre este fato.

Ocorram anúncios sonoros que indicavam a lotação completa do trem para aquele dia, não havendo a venda de passagens para aquele trem prestes a partir, porém a bilheteria estava aberta para a compra de passagens para outros dias. Foram ouvidas conversas entre pessoas que esperavam comprar passagens para aquele dia, porém decidiram realizar a viagem de ônibus.

A plataforma de embarque é acessada através de quatro portões, separados por tipo de passagem: um para venda online e prioridades, dois para venda presencial da classe econômica e um para a classe executiva. 0 trem é maior que a plataforma, por isso, ao parar, nem todos os vagões são acessíveis diretamente. Os carros destinados a classe econômica e aos deficientes tem acesso direto na plataforma, já os da classe executiva, têm o embarque realizado com auxílios de bancos retráteis que ajudam na ascensão ao carro.

Figura 4 - Estação Pedro Nolasco, Cariacica - ES

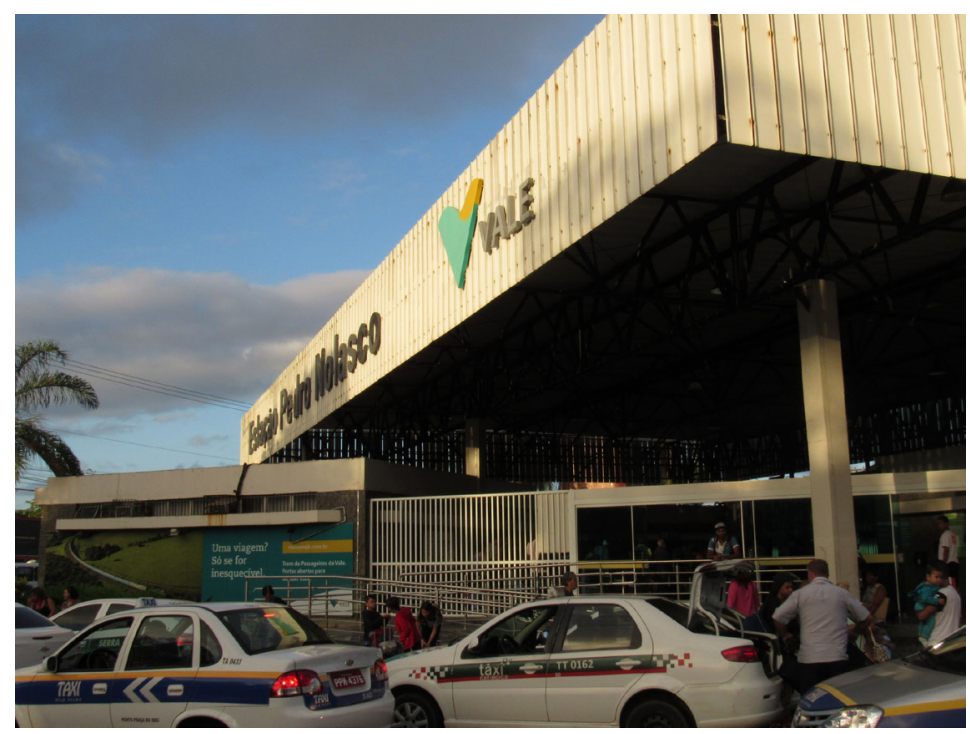

Fonte: Willi Jardim Costa Klink, 2017. 
Estação de Governador Valadares-MG

A estação de Governador Valadares se localiza no centro da cidade (Figura 5), e o desembarque é realizado por um portão ao fim da plataforma, passando-se por fora do terminal principal.

Ao desembarcar, nota-se diversos táxis para o serviço de transporte na cidade. Ao caminhar pela região, fora do horário de chegada dos trens, não foi possível encontrar uma oferta razoável de táxis. Há abordagens de pessoas oferecendo transporte para Vitória ou Belo Horizonte através de carros e vans. Essas pessoas procuram aqueles que não puderam embarcar no trem devido a sua lotação, questiona-se a legalidade da oferta destes serviços.

Para o embarque, há o mesmo procedimento de trocas de passagens para aqueles que compraram pela internet, as passagens já estavam previamente impressas e foram distribuídas por um profissional da estação. Anúncios sonoros de lotação do trem também foram ouvidos, não ocorria mais a venda de passagens para aquele dia.

0 acesso a plataforma é liberado às $12 \mathrm{~h} 45$, cerca de 20 minutos antes da chegada do trem, profissionais indicam em qual posição da plataforma o carro, descrito na passagem, irá parar, e há uma faixa amarela de segurança, demarcada no chão para evitar a aproximação de pessoas na vala dos trilhos, com repreensão verbal por parte dos funcionários para aqueles que ultrapassam a faixa sem a devida autorização. Nesta estação a plataforma comporta toda a extensão do trem.

Figura 5 - Estação de Governador Valadares-MG

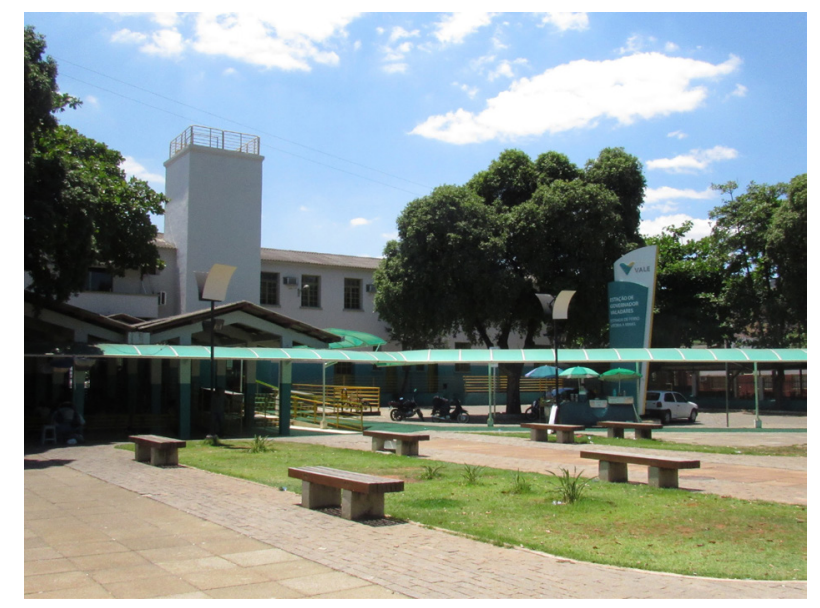

Fonte: Willi Jardim Costa Klink, 2017.

\section{Estação Ferroviária de Belo Horizonte-MG}

0 desembarque na estação de Belo Horizonte é tumultuado devido ao grande número de pessoas, sendo a capacidade total das composições de aproximadamente 1.100 pessoas. A plataforma fornece acesso ao carro adaptado para deficientes e os primeiros carros da classe executiva e econômica, devendo os passageiros dos outros carros, fazer o desembarque através de bancos auxiliares.

A estação é pequena (Figura 6) e fica congestionada em razão do grande número de pessoas que desembarcam, da circulação de carros e táxis, e de pessoas que abordam os passageiros na saída da estação. A rua de acesso à estação é estreita e fica paralisada com o grande número de pessoas. 


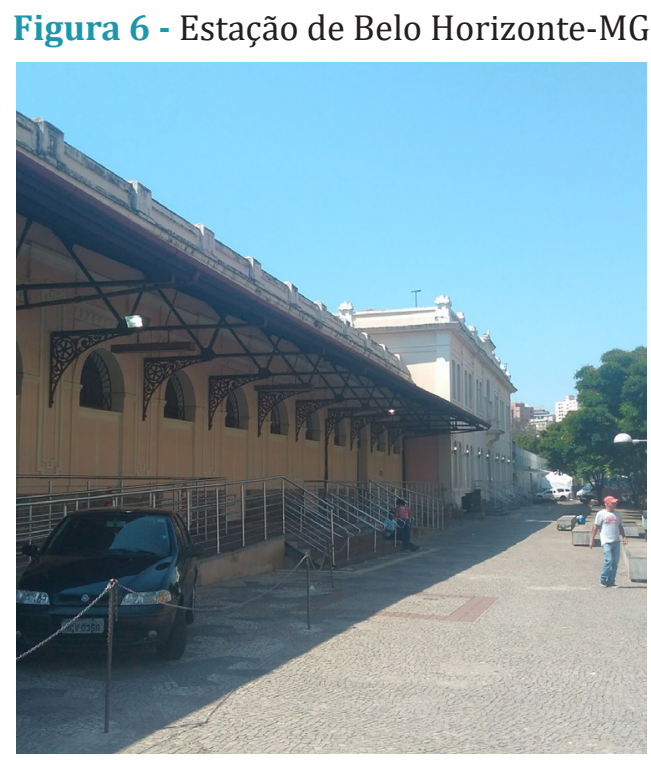

Fonte: Willi Jardim Costa Klink, 2017.

Fora dos horários de embarque e desembarque, é recomendado, pelos moradores locais, que não se ande pela área da estação, devido a seu alto grau de insegurança pública, porém ao caminhar pela região, foi possível perceber efetivos de forças policiais realizando rondas pela área.

A estação está conectada à rede de transporte público da cidade por meio do sistema de metrô e do sistema de ônibus BRT do município.

\section{CONFIGURAÇÃO E SERVIÇOS DOS TRENS}

Como explicado anteriormente, a Vale utiliza dois trens para o percurso principal na EFVM, para este relato serão denominados de trem 1 e trem 2.0 trem 1 é composto por 19 carros (vagões) mais a máquina locomotiva, tem capacidade total para 1.065 passageiros. Já o trem 2 é formado por 22 carros mais a locomotiva, com capacidade total para 1.122 passageiros.

0 trem 1 se configura pela seguinte disposição: 1 máquina locomotiva, 1 carro gerador, 4 carros de classe executiva, 1 carro lanchonete e cozinha, 1 carro restaurante, 1 para deficientes físicos, junto com espaços para a equipe do trem e 11 carros para a classe econômica.

0 trem 2 se configura pela disposição em: 1 máquina locomotiva, 2 carros geradores, 5 carros de classe executiva, 1 carro lanchonete e cozinha, 1 carro restaurante, 1 para deficientes físicos, junto com espaços para a equipe do trem, 11 carros para a classe econômica e 1 carro ambiental.

Na sequência são apresentadas descrições referentes a cada modalidade de carro do trem de passageiros, bem como os serviços apresentados a bordo, que foram visitados e experimentados pesquisador. 


\section{Máquina e geradores}

A máquina locomotiva (Figura 7) que transporta o trem de passageiros da EFVM usa da queima de biodiesel como forma motriz para puxar a composição (Vale, 2017b). Ela é auxiliada por um carro gerador, no trem 1, e dois carros geradores no trem 2 para a alimentação elétrica aos demais carros de passageiros.



Fonte: Willi Jardim Costa Klink, 2017.

\section{Carros executivos}

Os carros executivos se configuram com 57 assentos cada, com disposição em três fileiras. (Figura 8) São assentos na cor azul, mais largos, e com inclinação pneumática e descanso para os pés. Cada assento possui sistemas de som, iluminação e tomadas individuais. As bagagens podem ser acondicionadas nos compartimentos acima dos assentos ou nas prateleiras na traseira do carro. Todos os carros possuem banheiros separados por sexo e localizados fora do espaço das poltronas, mas acessível através de uma porta de acionamento por botão e fechamento automático. Todos os carros dessa classe possuem ar condicionado. 
Figura 8 - Carro executivo do trem de passageiros da EFVM

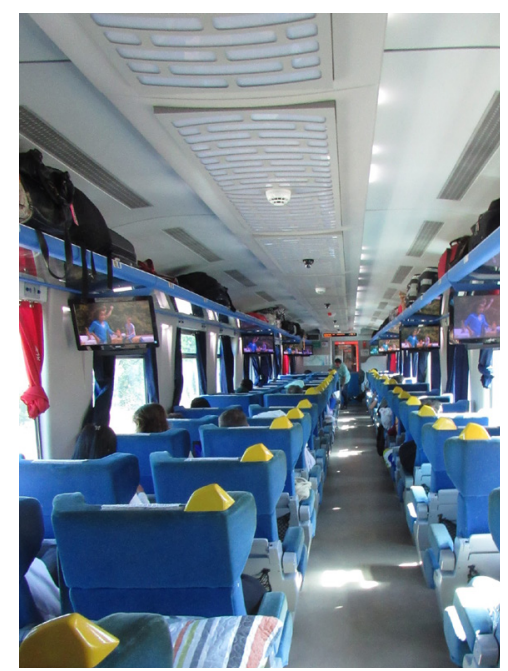

Fonte: Willi Jardim Costa Klink, 2017.

\section{Carros lanchonete e restaurante}

Os carros lanchonete e restaurante trabalham em conjunto, são gerenciados pela empresa terceirizada Bom Gosto. A lanchonete está conectada com a cozinha que prepara os alimentos a serem servidos por todo o trem. Ela fornece alimentos prontos aos que se dirigem ao balcão de atendimento. (Figura 9) Toda venda é cobrada em dinheiro efetivo, por falta de conexão para operação de máquinas de cartão de crédito e débito. Em certos momentos formava-se uma fila para adquirir alimentos na lanchonete devido a uma demora na operação do caixa, que alegava a falta de troco.

Figura 9 - Carro lanchonete do trem de passageiros da EFVM

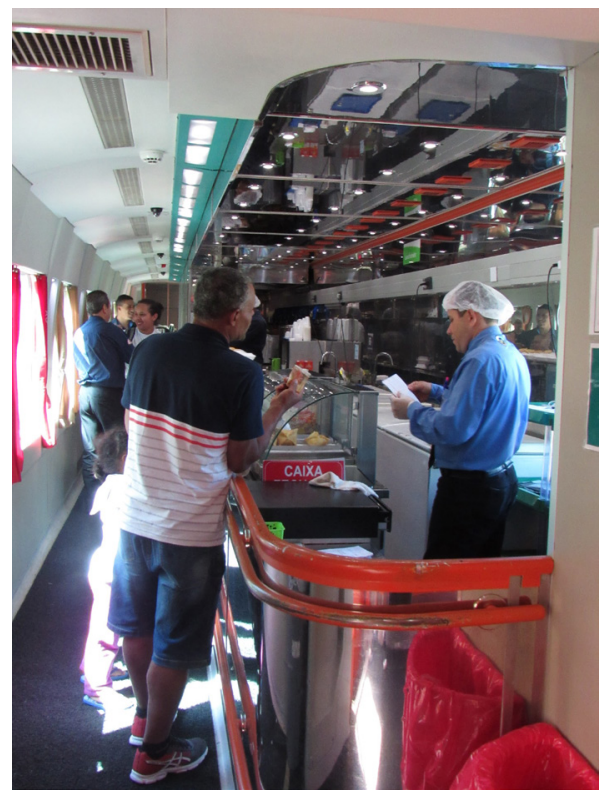

Fonte: Willi Jardim Costa Klink, 2017. 
0 vagão restaurante possui mesas com dois e quatro lugares, com capacidade total de 70 passageiros sentados, mais dois cadeirantes. (Figura 10) 0 passageiro pode se sentar, e consultar um cardápio para realizar os pedidos, dentre lanches, refeições, salgados, sobremesas e bebidas. 0 pedido é realizado para um garçom que então se dirige para a cozinha para realizar o prato. 0 pagamento em dinheiro é realizado no ato do pedido. 0 carro possui música ambiente e avisos sonoros indicam que os passageiros somente podem permanecer sentados em até 20 minutos após o recebimento do pedido, visando atender a todos os passageiros.

Figura 10 - Carro restaurante do trem de passageiros da EFVM

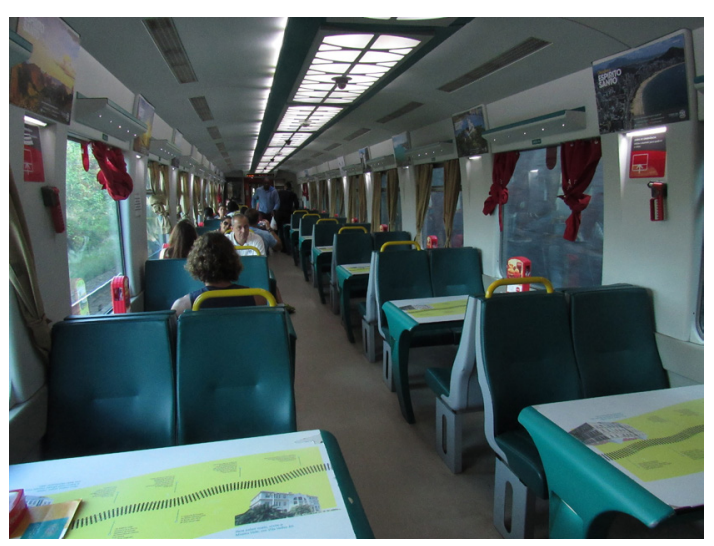

Fonte: Willi Jardim Costa Klink, 2017.

Carrinhos de venda percorrem os corredores de todo o trem para o serviço de bordo, nele são servidos salgados, doces e bebidas preparadas e de rápido consumo. Estes carrinhos permanecem nos corredores entre as fileiras, mas não impedem o trânsito de pessoas. Os responsáveis por esses serviço de alimentação, recolhem pedidos de pratos para o almoço, no valor de $\mathrm{R} \$ 14,00$ que são servidos me marmitas com arroz, feijão, frango e macarrão, disponíveis a partir das $11 \mathrm{~h} 30$ e entregues no assento da pessoa que o solicitou. Os pagamentos também são feitos somente em dinheiro.

Anúncios sonoros indicam que o serviço de alimentação a bordo é paralisado 20 minutos antes da chegada à estação de Governador Valadares e é retomado 20 minutos depois, isso decorre pela troca de turno das equipes.

\section{Carro especial}

O carro especial é destinado para passageiros com deficiências físicas e seus acompanhantes. Possui 4 assentos adaptados para receber cadeiras de rodas e mais 8 assentos para acompanhantes. (Figura 11) Ao fundo do carro há um banheiro adaptado unissex e as entradas do carro possuem elevador para embarque facilitado. 
Figura 11 - Carro especial do trem de passageiros da EFVM

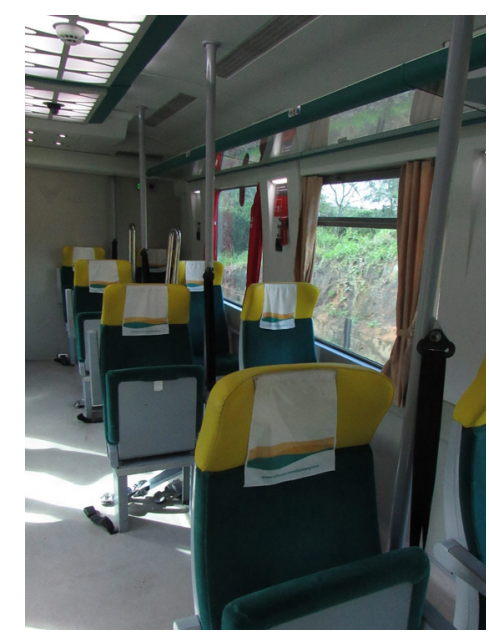

Fonte: Willi Jardim Costa Klink, 2017.

Esse carro também é compartilhado pela equipe que trabalha no trem, há uma sala destinada aos trabalhadores, uma sala de descanso e outra destinada ao chefe do trem, com designações visuais na porta de cada sala.

\section{Carros econômicos}

Os carros econômicos possuem 75 assentos cada, com disposição em quatro fileiras (Figura 12). São assentos em cor verde, com inclinação mecânica, porém sem descanso para pés. Os passageiros possuem acesso às tomadas elétricas que estão dispostas nas paredes e são compartilhadas por dois assentos, estas tomadas apresentam um bom funcionamento em ambos os trens. As bagagens também podem ser acondicionadas nos compartimentos acima dos assentos ou nas prateleiras na traseira do carro. Todos os carros possuem banheiros separados por sexo e localizados fora do espaço das poltronas, mas acessível através de uma porta com acionamento por botão e fechamento automático. Todos os carros dessa classe possuem ar condicionado.

Figura 12 - Carro econômico do trem de passageiros da EFVM



Fonte: Willi Jardim Costa Klink, 2017. 


\section{Carro ambiental}

Durante o percurso no trem 2, o sistema de informações por áudio da composição informa aos passageiros sobre as atividades do "Carro Ambiental" convidando para visitação. Para acessar este carro, bastava se direcionar para o final do trem, após o carro econômico de número 11 . 0 sistema de som também informa para os passageiros ficarem atentos para suas estações de desembarque ao visitar o carro ambiental, uma vez que o mesmo possui um sistema de som próprio, resultando na perda dos demais anúncios do trem pelos seus visitantes.

Ao visitar o carro ambiental nota-se dois ambientes, o primeiro, localizado na área frontal do carro, retrata o ambiente ecológico da Mata Atlântica, com representações fotográficas da fauna e flora do bioma, bem como representações sonoras do mesmo (Figura 13).

Figura 13 - Primeiro ambiente do carro ambiental do trem de passageiros da EFVM

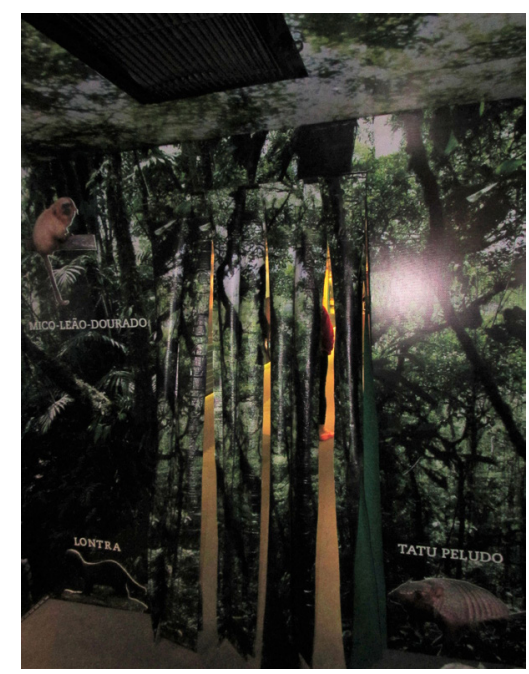

Fonte: Willi Jardim Costa Klink, 2017.

O segundo ambiente do carro possui uma área ampla, onde há uma monitora de serviço educativo que orienta atividades envolvendo os visitantes do carro e uma apresentação interativa localizada nas paredes do carro, que envolve atividades com informações sobre hábitos sustentáveis, energias renováveis, a política dos 5 R's (reduzir, repensar, reaproveitar, reciclar e recusar) e as cores de separação para coleta de lixo (azul: papel, vermelho: plástico; verde: vidro, amarelo: metal e cinza: não recicláveis.) (Figura 14). 
Figura 14 - Segundo ambiente do carro ambiental do trem de passageiros da EFVM

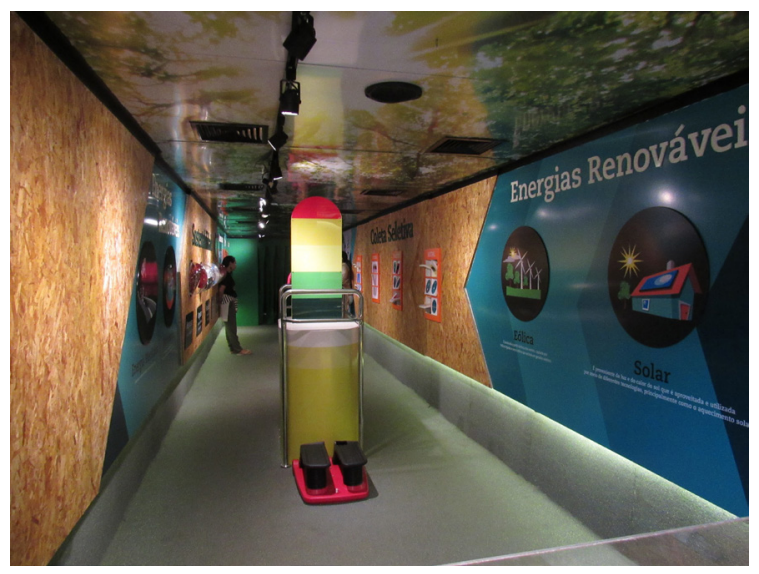

Fonte: Willi Jardim Costa Klink, 2017.

A monitora informou que este carro operava, antigamente, com o nome de "Vagão cultural" e contava com oficinas de atividades educativas voltadas para as crianças do trem, também possuía uma biblioteca infantil para leitura de livros no local. Este vagão cultural foi posto fora de circulação para uma remodelagem. O Carro ambiental, que foi inaugurado dois dias antes da visita (12 de outubro de 2017), em comemoração ao dia das crianças, não possui biblioteca infantil, mas oferece atividades recreativas e educativas para crianças e ampliou seu propósito para também atrair adultos.

\section{Serviços a bordo}

\section{Segurança, limpeza e serviço de bordo}

0 trem conta com uma equipe de dois guardas da empresa terceirizada Prosseguir, que realizam a ronda contínua entre os carros e são acionados via rádio caso ocorra algum incidente em que seja necessária intervenção.

Também como ações de segurança, são anunciados periodicamente avisos para os passageiros manterem consigo as passagens durante todo o percurso, para pais tomarem cuidado com suas crianças a bordo, ficar atentos com pertences e terem cautela ao se locomover pelos carros, para evitar acidentes e possíveis furtos ou roubos.

Além disso, durante o percurso total, foram anunciadas e realizadas quatro revisões de passagens, onde os funcionários do serviço de bordo checam as passagens de todos os passageiros, abordando aqueles que estão sentados em seus respectivos locais e aqueles que estão trafegando pela composição. A não apresentação da passagem pode acarretar na compra de uma nova passagem ou a eventual expulsão do trem.

O serviço de bordo é realizado por funcionários terceirizados da empresa Realma, que são responsáveis por receber e direcionar os passageiros para os assentos certos, responder dúvidas dos mesmos, e fazer os anúncios sonoros no trem, auxiliar no embarque e desembarque dos passageiros, além de realizar a venda de passagens para aqueles que embarcaram em paradas que não contam 
com venda de bilhetes físicos. Alguns carros da composição, são reservados para estas pessoas que realizam a compra da passagem a bordo do trem.

Os funcionários da Realma também realizam a limpeza do trem, varrendo o chão dos carros e recolhendo o lixo entre os assentos, separando lixo reciclável do não reciclável. Além disso, todos os carros possuem lixeiras apropriadas à coleta seletiva (Figura 15).

Figura 15 - Lixeiras para coleta seletiva do trem de passageiros da EFVM



Fonte: Willi Jardim Costa Klink, 2017.

\section{Sistema de Comunicação e Informação}

A comunicação com o usuário a bordo do trem é realizada por placas visuais, anúncios sonoros, sistema de entretenimento de bordo sem fio e monitores informativos.

As placas visuais indicam em qual carro o passageiro está ao embarcar ou ao percorrer o interior da composição e as numerações dos assentos dentro de cada carro (Figura 16). Indicam também as saídas de emergência, os extintores de incêndio, os banheiros, os botões de aberturas de portas, e os locais de risco ao toque. Além disso, os carros possuem mapas com o percurso do trem bem como a distância em quilômetros entre cada estação.

Figura 16 - Indicação luminosa do carro 3 econômico do trem de passageiros da EFVM

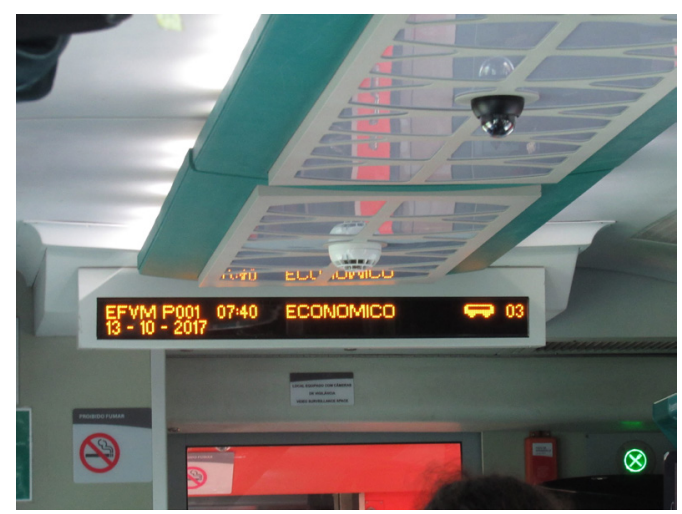

Fonte: Willi Jardim Costa Klink, 2017. 
As paradas e estações do percurso são anunciadas com cerca de 5 minutos de antecedência, bem como o tempo máximo de parada na estação e em que lado da composição as portas serão abertas. Em algumas paradas somente são abertas algumas portas do trem em determinados carros, isso acontece devido à pequena dimensão das plataformas das estações, para isso, ocorrem anúncios para os passageiros se dirigirem ao carro certo e realizar o desembarque. Em todas as paradas do percurso, há avisos para os passageiros tomarem cuidados com o vão entre o trem e a plataforma.

O sistema de entretenimento a bordo sem fio se configura no acesso a uma rede interna do trem através dos aparelhos eletrônicos dos passageiros que possuem acesso a redes wi-fi. Esse sistema oferece conexão a internet, porém ela é intermitente durante o percurso, sendo o acesso possível quando o trem adentra centros urbanos, e mesmo assim a conexão possui baixa velocidade. Os problemas com a conexão da internet são mencionados na página de abertura do sistema de entretenimento, e por causa disso, é oferecido um canal de entretenimento próprio, onde é possível assistir nove vídeos institucionais sobre a Vale, a EFVM e o seu trem de passageiros, 11 gravações de shows de artistas nacionais e internacionais e 34 filmes internacionais, dublados em português e com legenda no mesmo idioma. Esta opção opera com qualidade durante todo o percurso, não obtendo nenhuma oscilação de conexão.

0 trem também possui um sistema de entretenimento através de monitores informativos. Cada carro de passageiros na classe executiva e econômica possui nove monitores acoplados à parte superior do carro. Nestes monitores são exibidos vídeos e filmes do canal de entretenimento próprio do trem, sendo que na classe econômica os filmes são exibidos com áudio aberto, enquanto na classe executiva os monitores são silenciosos, e os áudios do vídeo exibido podem ser acessados através das saídas de fones de ouvido presentes em cada poltrona.

Estes monitores também transmitem informações ligadas à atividade turística atrelada ao percurso do trem, uma vez que, quando um filme não é exibido no momento e o trem se aproxima de uma determinada parada, é exibido um pequeno vídeo com curiosidades históricas, demográficas e turísticas da cidade da parada referida.

0 trem também transmite outras informações turísticas para os seus passageiros, como a exibição de vídeos informativos do Trem Turístico da Vale, que realiza o percurso entre as cidades de Ouro Preto e Mariana em Minas Gerais. Ocorre também a exibição de um vídeo informativo do Museu da Vale, localizado no município de Vila Velha, na Região Metropolitana de Vitória, ES, museu este que transmite um pouco da história da EFVM. Além disso, no carro de passageiros, diversos quadros publicitários são expostos com o objetivo de divulgar o turismo no Estado do Espírito Santo.

Como anúncio final do trem, ao adentrar à cidade de Belo Horizonte, é requisitado aos passageiros que confiram os seus pertences e tomarem cuidado com o vão entre o trem e a plataforma ao desembarcar, para isso, pedem para manterem a calma no desembarque pois o tempo para a ação será suficiente para todos a realizarem com segurança. Por fim, anunciam que foi um prazer ter todos os passageiros a bordo e que esperam recebê-los novamente em breve. 


\section{ANÁLISE - É TURISMO FERROVIÁRIO?}

Este meio de transporte objetiva promover principalmente o desenvolvimento regional ao servir como um modal de conexão entres as cidades do Espírito Santo e Minas Gerais mencionadas na Figura 1.

0 trem de passageiros EFVM consiste em um meio de transporte mais barato comparado a outros modais que oferecem rotas entre os pontos extremos da ferrovia. Entretanto, se for feita uma comparação entre o tempo de viagem de trem, avião e ônibus, de rotas comerciais regulares, a diferença monetária acaba não sendo tão vantajosa, como mostra o Quadro 1.

Entretanto, observa-se que o trem se constitui em uma das poucas opções de transporte entre municípios do interior dos dois estados que percorre, o que deve explicar o fato das passagens se esgotarem na maioria das estações de embarque e desembarque. Isso reforça a importância do trem de passageiros como fator que promove o desenvolvimento local e regional porque funciona como um elo de ligação entre pessoas e negócios.

A observação participante permitiu constatar que a maioria dos passageiros entendem o trem como somente um meio de transporte, sem fazer qualquer relação com seu potencial turístico. Além disso, não se percebeu a presença de estrangeiros, famílias ou indivíduos com máquinas fotográficas ou que tivessem características de turistas, pessoas que não estão em uma região de moradia habitual, como era o caso do pesquisador.

Destaca-se que o trem de passageiros é valorizado pela sua operadora, a Vale, uma vez que oferece este serviço diariamente e este tem prioridade na via férrea frente as composições de carga.

Os serviços terceirizados são adequados para a oferta de uma viagem segura, confortável e com pontualidade relativa. Considera-se que as poltronas são confortáveis e garantem boa acomodação, o entretenimento é adequado e atende diversas faixas etárias, o serviço de bordo é variado, mas possui estrutura reduzida para atender todos os passageiros, o efetivo de segurança é eficiente e os anúncios são esclarecedores sobre as regras do trem e da organização realizada para as paradas pelo percurso. Entretanto, todas as informações são prestadas apenas no idioma português, o que pode ser considerado como um fator limitante para atrair turistas estrangeiros.

A beleza cênica do percurso constitui-se em um relevante atrativo para turistas. 0 trem, percorre paisagens do vale do Rio Doce e dos mares de morros mineiros, que são únicas e não podem ser vistas se o percurso for feito por outro modal de transporte. Também é elogiável o incentivo dado às qualidades turísticas das cidades que o trem cruza em seu percurso, através da exposição de vídeos informativos no sistema de entretenimento de bordo. Outros elementos vivenciados na viagem e que são de interesse para o lazer e turismo são: o serviço educativo oferecido no Carro Ambiental, a orientação sobre a coleta seletiva, a divulgação do Trem Turístico da Vale, entre Ouro Preto e Mariana e do Museu da Vale em Vila Velha.

Por fim, agrega-se a este transporte o valor turístico da nostalgia, uma vez que o modal ferroviário teve anos de glamour na antiguidade e hoje é uma raridade no território nacional e, portanto, o trem de passageiros da EFVM constitui-se em 
uma, entre as duas únicas possibilidades, de experiência de viagem ferroviária de longa distância no Brasil.

Diante do exposto o trem de passageiros da EFVM é um atrativo turístico porque promove a possibilidade da apreciação do caráter cênico do percurso e também propicia o sentimento nostálgico a quem o utiliza, uma vez que resgata a história do trem e das cidades em que ele passa, através da disposição de vídeos em seus serviços de comunicação e entretenimento a bordo.

Entretanto, este modal apresenta certos pontos negativos que merecem serem mencionados porque interferem na qualidade da experiência turística. A exemplo disso, observou-se que as estações de grande movimentação de passageiros (e.g. Pedro Nolasco e Belo Horizonte) não são confortáveis para os passageiros visto o grande fluxo de pessoas. A venda pela internet também promove o rápido esgotamento das passagens disponíveis nas composições o que pode colaborar com a oferta de transporte alternativo nas entradas das estações.

\section{CONSIDERAÇões finats}

0 trabalho foi concluído conforme proposto ao fornecer um relato das experiências vividas pelo pesquisador ao realizar o percurso do trem de passageiros da EFVM, para tanto, foram apresentados registros fotográficos que auxiliaram a ilustrar a realidade apresentada por este serviço. Foram também descritas a infraestrutura do trem, de suas vias e das estações visitadas, bem como os serviços oferecidos aos passageiros. Por fim, foi permitida uma análise sobre a potencialidade do trem de passageiros EFVM como atrativo turístico, por meio da descrição dos elementos que o favorecem e o prejudicam.

Acredita-se que seja importante desenvolver novos trabalhos que possam materializar a análise crítica de um pesquisador na área de turismo que vivencia uma experiência turística.

Enaltece-se este espaço aberto pela Revista Turismo em Análise para agregar à literatura científica brasileira relatos que podem servir, no futuro, para estudos históricos e comparativos, que permitirão avaliar o percurso de empresas, negócios e atrativos turísticos que atuam no Brasil.

\section{REFERÊNCIAS}

Allis, T. (2006). Turismo, patrimônio cultural e transporte ferroviário: um estudo sobre as ferrovias turísticas no Brasil e na Argentina. (Dissertação de Mestrado). Recuperado de http://www.teses.usp.br/teses/disponiveis/84/84131/tde.../Dissertacao_Thiago_Allis. pdf

Brasil. Ministério dos Transportes, Portos e Aviação Civil. (2015). Transporte ferroviário turístico de passageiros. Brasília, DF. Recuperado de http://www.transportes.gov.br/bit-menu-item.html

Clickbus. (2017). Compre a sua passagem de ônibus agora! Recuperado de https://www. clickbus.com.br/

CNT, Confederação Nacional do Transporte. (2013). O sistema ferroviário brasileiro. Brasília, DF: CNT. Recuperado de http://www.cnt.org.br/Publicacoes/estudo-cnt 
CNT, Confederação Nacional do Transporte. (2016). Transporte e desenvolvimento: transporte metroviário de passageiros. Brasília, DF: CNT. Recuperado de http://www.cnt.org. br/Publicacoes/estudo-cnt

Cooper, C. et al. (2007). Turismo: princípios e práticas. Porto Alegre, RS: Bookman.

Decolar (2017). Encontre o seu voo. Recuperado de https://www.decolar.com/

Fraga, C. C. L. (2011). Contribuição metodológica para a implantação de trens turísticos no Brasil. (Tese de Doutorado). Recuperado de http://objdig.ufrj.br/60/teses/coppe_d/ CarlaConceicaoLanaFraga.pdf

Fraga, C. C. L. \& Castro, R. T. (2012) Introdução aos transportes ferroviários: parte 1. In: Fraga, C. C. L., Fernandes, E. M. R. \& Castro, R. T. Transporte. (p.p. 93-120) Rio de Janeiro, RJ: Fundação CECIERJ/Consórcio CEDERJ.

Lohmann, G; Fraga, C. \& Castro, R. (2013). Transportes e destinos turísticos: planejamento e gestão. Rio de Janeiro, RJ: Elsevier.

Palhares, G. L. (2002). Transportes turísticos. São Paulo, SP: Editora Aleph.

Vale. (2017a). Trem de Passageiros. Recuperado de http://www.vale.com/brasil/PT/business/logistics/railways/trem-passageiros/Paginas/default.aspx

Vale. (2017b). Conheça nossa frota. Recuperado de http://www.vale.com/brasil/PT/business/logistics/railways/Passenger-Train-Vitoria-Minas/Paginas/sobre.aspx

Vale. (2017c). Início. Recuperado de http://www.vale.com/brasil/PT/business/logistics/railways/Passenger-Train-Vitoria-Minas/Paginas/default.aspx

Vale. (2017d). Rotas. Recuperado de http://www.vale.com/brasil/PT/business/logistics/railways/Passenger-Train-Vitoria-Minas/Paginas/rotas.aspx

Vale. (2017e). Informações sobre a viagem. Recuperado de http://www.vale.com/brasil/ PT/business/logistics/railways/Passenger-Train-Vitoria-Minas/Paginas/infos.aspx

Vale. (2017f). Cartilha de regras de uso. Recuperado de http://www.vale.com/brasil/PT/ business/logistics/railways/Passenger-Train-Vitoria-Minas/Documents/VA055-16_folder_regras_A4_5.pdf

Veal, R. G. (2011). Metodologia de pesquisa em lazer e turismo. São Paulo, SP: Editora Aleph.

\section{Contribuição}

Willi JARdim Costa KLink: Autor ÚNICO 